\title{
From Knowledge Transmission to Sign Sharing: Semiotic Web as a New Paradigm for Teaching and Learning in the Future Internet
}

\author{
Noël Conruyt, Véronique Sébastien, Olivier Sébastien, \\ David Grosser, and Didier Sébastien
}

\begin{abstract}
LIM-IREMIA, EA 25-25, University of Reunion Island, 97490, Sainte-Clotilde, France \{noel.conruyt, veronique.sebastien, olivier.sebastien, david.grosser, didier.sebastien\} @univ-reunion.fr
\end{abstract}

\begin{abstract}
In the $21^{\text {st }}$ century, with the advent of ultra high-speed broadband networks (1Gb per second), the Internet will offer new opportunities for innovators to design qualitative services and applications. Indeed, the challenge of such e-services is not only on the technological aspects of Internet with new infrastructures and architectures to conceive. The reality is also on its human and multimedia content delivery, with innovative philosophies of communication to apply in this digital and virtual age. In the context of Teaching and Learning as a human-centered design approach, we propose a new paradigm for thinking the Web, called the Web of Signs, rather than the Web of things. It focuses on the process of making knowledge by sharing signs and significations (Semiotic Web), more than on knowledge transmission with intelligent object representations (Semantic Web). Sign management is the shift of paradigm for education with ICT (e-Education) that we have investigated in such domains as enhancing natural and cultural heritage. In this paper, we will present this concept and illustrate it with two examples issued from La Reunion Island projects in instrumental e-Learning (@-MUSE) and biodiversity informatics (IKBS). This Sign management method was experimented in the frame of our Living Lab in Teaching and Learning at University of Reunion Island.
\end{abstract}

Keywords: Semiotic Web, Sign management, E-service, Education, Living Lab, Creativity Platform, Future Internet.

\section{$1 \quad$ Introduction}

The Future of Internet is not only a matter of technological, economical, or societal awareness; it is also grounded in individual, environmental and cultural values. Psychological, ethical, biological and emotional properties are indeed drivers of the Future Internet in a perspective of sustainable development of services with people. Although the Internet is the interconnection of networks of computers, it delivers interactive human-machine services such as the Web or Email [1]. The Web is an information service available on Internet with access to personalized documents, images and other resources interrelated together by hyperlinks and referenced with 
Uniform Resource Identifiers (URIs). Email is also a communication service available on the Internet. Nevertheless, Information and Communication Technologies (ICT) are not only oriented on technologies, but also convey human contents (data, information, and knowledge) that are communicated between end-users. At this upper level, co-designing e-services are means to connect producers and consumers of multimedia contents, in order that infrastructures of Future Internet meet user needs [2]. These principles have been adopted since 2006 by the European Network of Living Labs and are developed in the frame of corresponding literature [3].

Our idea is that in the Future Internet, we must not only pay attention to the quantity of information that is exchanged at higher speed between internauts (which is a techno-centric and economic perspective), but also to the quality of information communicated between people for them to be educated and aware of the richness and fragility of their environment. In the first case, users become stunned prosumers (producers and consumers of information), and in the second case they are simply responsible citizens (sensitive and educated people) in a closed world that must be preserved for the next generations.

In order to deliver such a holistic e-service in education, we introduce our methodology of Sign management in the first part of this paper. Then we explain how we organize the different types of Web that are part of the Semiotic Web, what makes its sense, and how to pass from Knowledge transmission to Sign sharing. This is illustrated with two examples taken from ICT projects for music education and biodiversity management. The conclusion emphasizes the need for repositioning human concerns at the center of technologies, and why we should favor the development of Living Labs philosophies.

\section{$2 \quad$ Sign Management}

The reality of Future Internet is that it supports both technological and content services over the physical network. But in the $21^{\text {st }}$ century, the technology must be at the service of human content and not the contrary. Indeed with Web 2.0, we have entered an era where usage is the rule for making e-services. Personalization of product/services accessible throughout the Internet is becoming more and more important as innovation is opening [4] and democratizing [5]. But we will have also to manage the quality of information that is exchanged between people in order that knowledgeable persons can express their know-how and be acknowledged [6] for it. In the context of climate change, biodiversity loss, pollution and globalization, it is urgent that the Future of Internet enhances scientific voices at human level.

But this endeavor cannot be led only by managing knowledge of specialists with the technology of Semantic Web, so-called Web 3.0 [7]. Knowledge management is not enough for the Future Internet.

Firstly, knowledge cannot be managed because it resides between the ears of somebody (tacit knowledge). Only information that is transmitted between persons can be managed. 
Secondly, Knowledge can be found in books written by specialists (explicit knowledge), but this is dead knowledge that cannot be updated. Knowledge is the result of a long experience of some experts that have experimented a lot of cases in the fields, and formed their know-how by compiling them in their mind. This know-how is living knowledge and it can be managed with multimedia contents (see below for music learning).

Thirdly, the response of ICT to tackle knowledge management is to propose Semantic Web as a solution. Indeed, this is necessary in the context of representing objects of knowledge in computers with formats coming from description logics (RDF, OWL), but it is not sufficient as far as this technology cannot capture the signification of these objects for different individuals, i.e. Subjects.

In the context of enhancing Knowledge with ICT, we propose Sign Management as a shift of paradigm for the Future Internet. It emphasizes the engineering and use of data, information and knowledge from the viewpoint of a Subject. This concept is derived from the pragmatic Peirce's theory of semiotics with a Sign's correspondence of the Subject to its Object. From this philosophical viewpoint, a Sign, or representamen, is something that stands to somebody for something in some respect or capacity [8]. From our computer science analysis, Data (Object) is the content of the Sign (something), Information, a multi-layered concept with Latin roots ('informatio' = to give a form) is its form, and Knowledge is its sense or meaning, i.e. no-thing. The notion of Sign is then more central than knowledge for our purpose of designing e-services.

In Figure 1, we define a Sign as the interpretation of an Object by a Subject at a given time and place, which takes into account its content (Data, facts, events), its form (Information), and its sense or meaning (Knowledge).

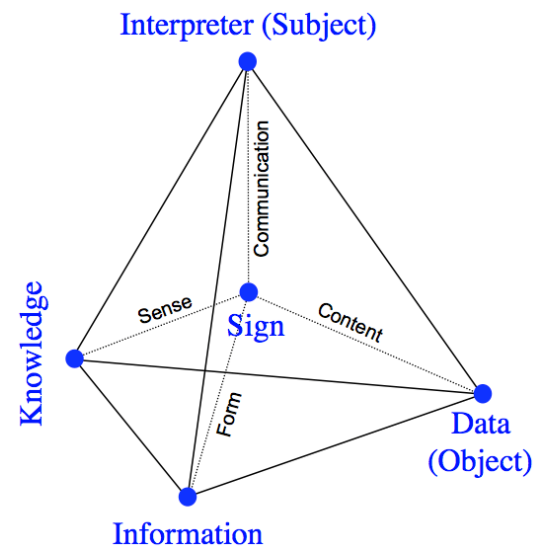

Fig. 1. The tetrahedron of the Sign

Then in Figure 2, we introduce Sign-ification, the continuous process of using Signs in human thinking for acquiring Objects interpreted by Subjects.

This signification process or Semiosis takes the different components of the Sign in a certain order to make a decision: first comes the Subject or Interpreter who is receptive to his milieu or "Umwelt" [9], and who cares about Information to act in a certain 
direction (volition), then occurs the searched Data (Object) to position himself in space and time (action), then Knowledge is activated in his memory to compare the actual situation with his past experiences and make an hypothesis for taking a decision (cognition). The Signification or the building of the sign communicates the process iteratively in a reflexive way (in order to memorize new knowledge) or communicates the resulting interpretation as information to its environment (by exteriorization).

Semiosis is similar to the working principle of inference engine that was modeled in expert systems: the evaluation-execution cycle [10]. The difference is that Signification integrates the Subject in the process, and this integration is therefore more meaningful to humans than to machines. The Subject operates on Signs in two phases: reflection and action. These phases are inter-linked in a reflexive cycle with a semiotic spiral shape including six moments: 1) to desire, 2) to do, 3) to know, 4) to interpret, 5) to know-how for oneself, 6) to communicate to others (Figure 2). The semiosis spiral is included in the tetrahedron of the Sign.

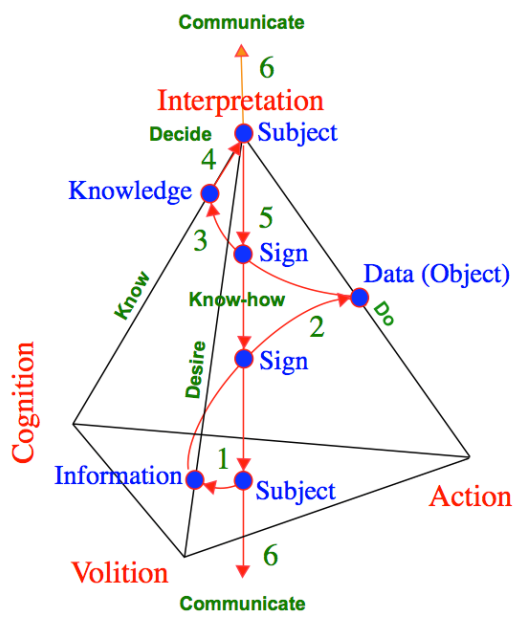

Fig. 2. The signification process for Sign management

Consequently, Signification is the key psychological process that makes sense for practicing usage based research and development with people by communicating data, information and knowledge.

Signification is the kernel of Semiotic Web although Representation is at the root of Semantic Web. Both are necessary to co-design e-services in the Future Internet, but from our experience, don't miss Sign management and Semiotic Web if you want to co-design e-services with end-users!

\section{Semiotic Web}

Making sense or signifying is a biological characteristic that cannot be eluded in the Future Internet. We are acting now on a limited planet and the objective is to render 
services to human beings and become responsible rather than serve oneself and consume even more energy and matter with the help of computers.

When an organism or an individual seeks for something, his attitude is to pay attention to events of his environment that go in the sense (direction) of what he searches. The primary intention of a microorganism such as bacteria is "good sense": it wants to capture information from the milieu to develop itself and stay alive [11]. Human development follows the same schema of self-organized living systems at more complex levels than these physiological and safety needs. They are those that have been defined in the hierarchy of fundamental individual needs: love, belonging, esteem, self-actualization [12]. As a consequence, we hold that before being able to make "true sense", i.e. adopt a scientific rationale, the objective of individuals is to respond to psychological needs (desire, pleasure, identity, etc.). This theory of human motivation is a natural and cultural hypothesis, which is corroborated by Umwelt [9], Activity [13] and Semiotic [8] pragmatic theories. These life and logical sciences are components of the Biosemiotics interdisciplinary research [14], which was introduced before the advent of Internet as the "Semiotic Web" [15].

Semantic Web is the dyadic combination of form and sense of the linguistic Sign [16], taken as a signifier (form) and signified (sense). It is rational. Semiotic Web is more generic and living. It complements the Semantic Web (form and sense) with the referents (content) that are observed data (interpretations) geo-referenced in a $3 \mathrm{D}$ information world (Immersive Web) as Web Services by subjects pertaining to communities of practice (Social Web 2.0). This makes our Sign management ecosystem a tetrahedron model (Figure 3) that is more involved in concrete life with end-users on a specific territory such as Reunion Island.

The Web of Signs combines:

1. The Web of Data and Objects, i.e. the flow of raw and digital contents produced by specialists (teachers) and transmitted by engineers in databases and knowledge bases in the frame of an Information System (one-way flow), but progressively becoming interoperable through Web services with other Information Systems,

2. The Web of Subjects, i.e. a bidirectional communication platform between users (teachers and learners) using different e-services within a community of practice to exchange interpretations of data and objects, and negotiate their value,

3. The Web of Information that is geo localized in attractive virtual worlds representing the real landscape (metaverses), and accessible at any time, anywhere, on any devices (mobiquity).

4. The Web of Knowledge for machines to communicate logically on the basis of a formal, open and semantic representation of data and objects,

At the University of Reunion Island, we have investigated each of these dimensions that are converging to form what we call the Semiotic Web. As the World is an Island and as Reunion Island is a small world, we designed our Living Lab as a small laboratory for Teaching and Learning Sciences and Arts by Playing [17]. Indeed, edutainment is one of the pillars of the Future Internet [18]. With game-based learning, we consider that we can play seriously to better know our environment and then better protect it. 


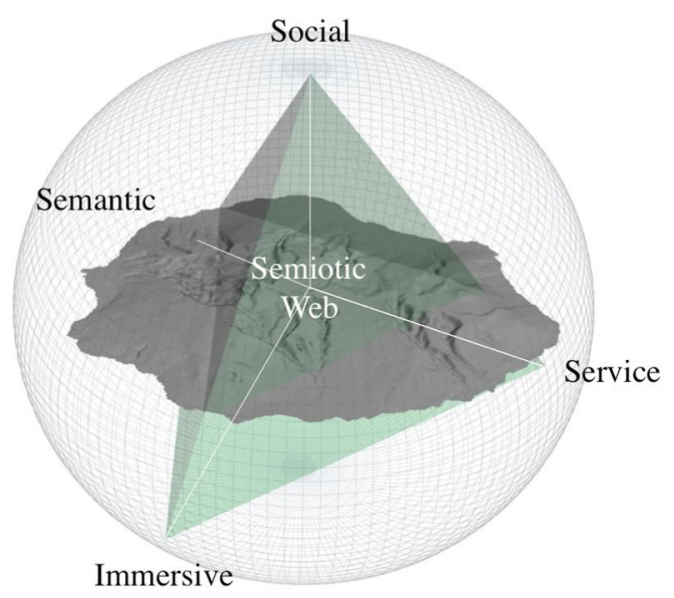

Fig. 3. The Situated Service, Social, Semantic and Immersive Web

For biodiversity management for example, we co-designed an Immersive Biodiversity Information Service (IBIS) for helping biologists and amateurs to access to forest and coral reef species information. This Teaching and Learning tool intends to use different modules dedicated to certain functionalities at different levels of data, information and knowledge and let them communicate by using Web Services [19].

In the spirit of Web 2.0 technologies, we participate to the ViBRANT FP7 project [20] that uses the Scratchpads for data sharing. Using a content management system (Drupal), Scratchpads 2.0 enables bottom up, collaborative work between all types of naturalists, from researchers to amateurs. This Social Web tool supports communities of taxonomists to build, share, manage and publish their data in open access.

For computer-aided taxonomy, we developed an Iterative Knowledge Base System platform called IKBS [21] with some taxonomists. It is based on a knowledge acquisition method and an observing guide for describing biological objects, i.e. the descriptive logics in life Sciences [22]. Our descriptive logics must not be confused with description logics (RDF, OWL) of the Semantic Web because they are the rules of thumb of experts for making descriptive models (ontologies) and describing cases. The objective of this Research tool in Biodiversity Informatics is to help biologists classify and identify a specimen correctly from an expert viewpoint by using ontoterminologies (ontologies + thesaurus).

\section{From Knowledge Transmission to Sign Sharing}

Knowledge is subjective in the paradigm of Sign management: it cannot be taken for granted without putting it into use, mediated and negotiated with other Subjects on a meeting place, which we called a Creativity Platform [23]. What can be managed is called descriptive or declarative knowledge: it is the communication of justified true beliefs propositions from one Subject made explicit. The formal interpretation process from observation to hypotheses, conjectures and rules is called signification 
of knowledge on the human communication side of the Sign. It is called representation or codification of knowledge on the machine information side of the Sign. Apart from being described, this interpretation process can be shown with artifacts to illustrate the description ("draw me a sheep", says the little prince!). Sign management wants to enhance this aspect of multimedia illustration of interpretations to facilitate transmission and sharing of knowledge through the communication of the Subject (see the fourth communication part of the sign in Figure 1).

In knowledge management, propositional knowledge is taken mostly in the sense of scientific knowledge, considered as objective in scientific books, and providing the know-that or know-what. Ryle in [24] has shown that this is confusing. In the sense of subjective knowledge taken as "I know that or I know what", there is the other sort of knowledge called know-how. It is "the knowledge of how to do things", i.e. what the subjects can show through their interpretations when they practice their activity (there is a difference between the recipe and the cooking of the recipe, isn't it?). And some people do the activity better than others. They are called the experts. As such, knowhow is closer to data (Praxis) and information (Techne) than to knowledge (Scientia). Finally, know-how and know-that or know-what are different categories of knowledge and should not be conflated [25]. Knowledge synthesizes what makes sense in the head of skilled persons for doing well the tasks of their activity.

Starting from these differences of interpretations about the term of knowledge, and considering the domain of activity that we want to deal with, i.e. education with ICT, we prefer to focus on managing interpretations, and firstly the good ones from professors. Sign management manages live knowledge, i.e. subjective objects found in interpretations of real subjects on the scene (live performances) rather than objective entities found in publications (bookish knowledge).

In this context of managing know-how rather than knowledge, we have set-up our Living Lab in Reunion Island on the thematic of Teaching and Learning by Playing [26]. The sharing of expertise with ICT is our added value in education for some specific domains such as managing biodiversity, performing art (music, dance, etc.), speaking a language, welcoming tourists, or cooking. These niches can be enhanced with ICT in a sustainable manner by following some innovative methods. For example, sign or know-how management produces sign bases that are made of interpretations for knowing how-to-do things with multimedia content and not only knowing what are these things in textual Knowledge bases.

Finally, a Sign is a semiotic and dynamic Object issued from a Subject and composed of four parts, Data, Information, Knowledge and Interpreter. Our Sign paradigm uses a fouradic representation (a regular tetrahedron, see Figures 1 and 2) instead of the triadic sign representation that lets the Subject outside of the Semiosis process. All these subjective components communicate together to build a chain of significations and representations that we want to capture.

Sign management makes explicit the subjective view of doing arts and sciences. Our aim is to compare different interpretations of subjects about objects through transmitting and sharing them on a physical and virtual space dedicated to a special type of e-service, i.e. in instrumental e-learning or biodiversity informatics (see below). For the purpose of co-designing such a service with ICT, the Creativity Platform 
is the co-working, co-learning and communication space for researchers and developers, businesses and users, aimed at collectively defining the characteristics of eservices in order to ensure the most direct correspondence between expectations and use [27].

In its technical form (see Figure 4 on the right), the Creativity Platform includes a multimedia platform as the one that we find in television studios, but also includes a physical and virtual place to discuss ideas and projects, make models and prototypes, and experiment them in a synchronous (focus group) or asynchronous (video forum on the Internet) way.

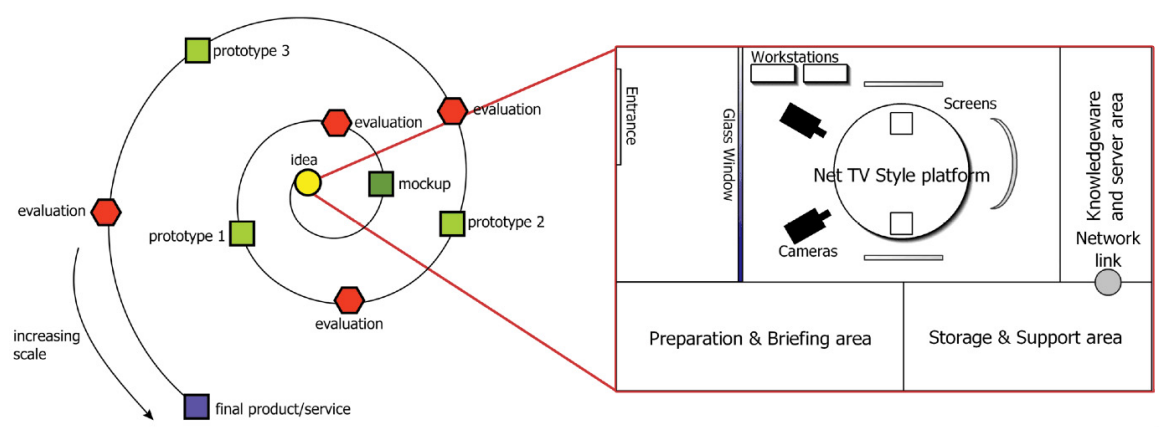

Fig. 4. The Creativity or Co-design Platform to experiment future products/services

Sign sharing makes use of the Creativity Platform by applying an iterative assessment process with end-users from the idea to the product/service through mock-ups and prototypes. We will now illustrate this method with examples in instrumental eLearning and biodiversity informatics.

\section{$5 \quad$ Sign Sharing in Music Teaching and Learning}

Sharing Signs is particularly relevant in artistic fields, where a perfect synchronization between gestures, senses and feelings is essential in order to produce original and beautiful works.

In this frame, the @-MUSE project (@ nnotation platform for MUSical Education) aims at constituting a Musical Sign Base (MSB) with the interactions coming from a community of musicians. This project benefits from the experience we accumulated in the field of instrumental e-Learning in Reunion Island, from various mock-ups to complete projects such as e-Guitare [23]. Figure 5 sums up our research process in this domain, based on a Creativity Platform.

While the different versions of e-Guitare were more centered on the teacher performance, the FIGS (Flash Interactive Guitar Saloon) service was more axed on the dialog between learners and teachers through an online glosses system. What principally emerged from these projects was the need to facilitate the creation and maintenance of new content on the platform. Indeed, while those projects required the intervention of computer scientists and graphic designers in order to create 
high-quality resources, @-MUSE aims at empowering musicians into creating and sharing their lessons by themselves, on the basis of a common frame of reference: the musical score.

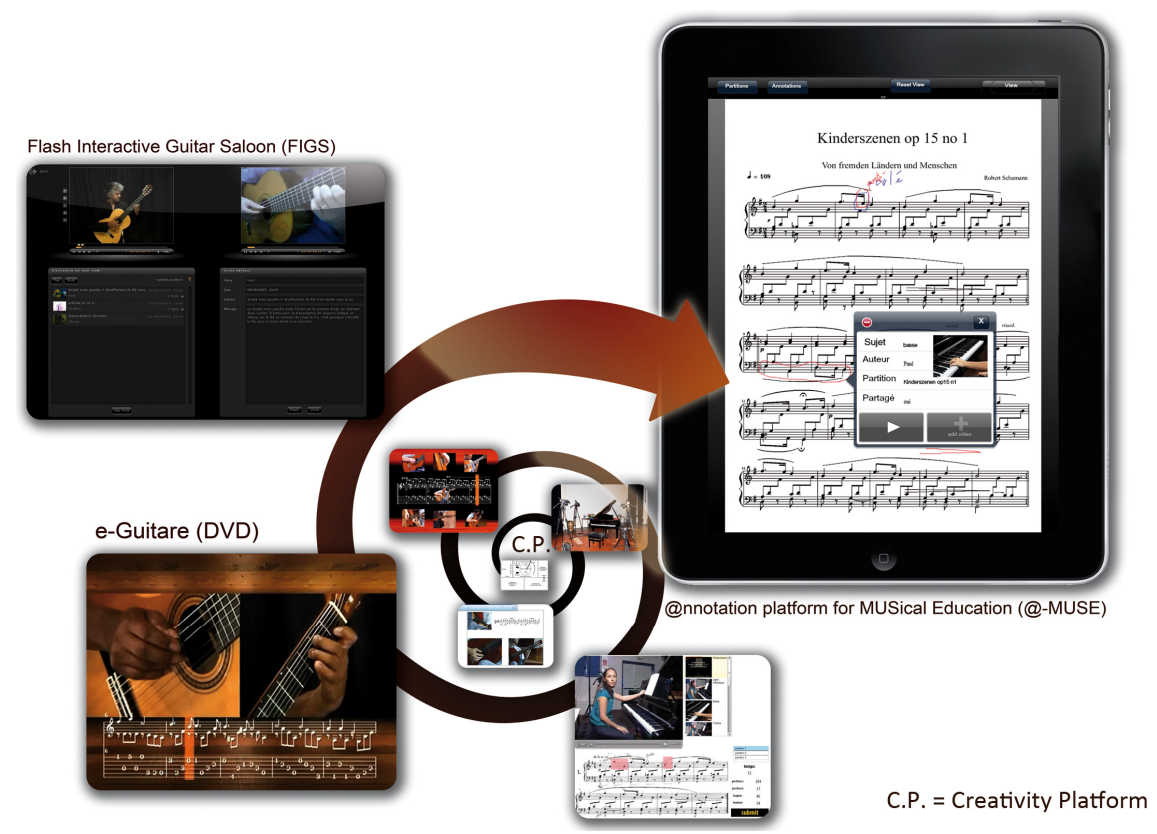

Fig. 5. Instrumental e-Learning services co-designed on a Creativity Platform (CP)

To do so, we designed a MSB. It consists in a set of annotated performances (specimen, or instance) each related to a given musical work (species, or class). This base can be used to compare various performances from music experts or students, and also to dynamically build new music lessons from the available content. To do so, we define a Musical Sign (MS) [28], as an object including a content (a musical performance or demonstration), a form (a score representing the played piece) and a sense (the background experience of the performer, what he or she intends to show) from the viewpoint of a subject (the creator of the Sign).

Figure 6 describes the composition of a MS that can be shared on the platform through a multimedia annotation. Indeed, the principle of @-MUSE is to illustrate abstract scores with indexed multimedia content on top of MusicXML format [33] in order to explicit concretely how to interpret them. Besides, as shown on Figure 6, multimedia annotations embed all three components of a Sign (data, information and sense). This procedure is inspired from a common practice in the music education field, which consists in adding annotations on sheet music in order to remember tips or advice that were validated during the instrumental practice [29]. 


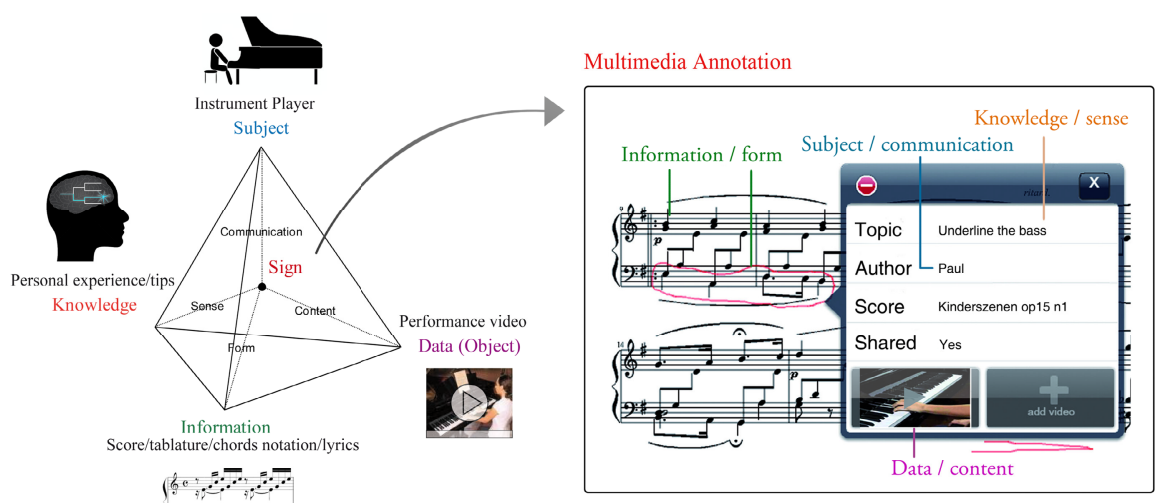

Fig. 6. The musical sign tetrahedron illustrated with a multimedia annotation on @-MUSE

Figure 7 presents an example of such practice on an advanced piece for the piano, where annotations indicate tips to overcome technical and expressive difficulties, and underline points to improve for the learner. Grounding the @-MUSE service on this practice insures a transparent and natural usage for musicians who already annotate their scores by hand, and additionally enables them to show what they mean using multimedia features. As such, @-MUSE empowers musicians into creating their own interactive scores, using for instance mobile tablets equipped with webcams (@ MUSE prototype [30]).

Naturally, our platform usage on mobile devices is particularly relevant as music is rarely practiced in a classroom, in front of a computer, but rather in informal situations (in front of a music stand, at home or with friends). Moreover, recent tablets featuring advanced tactile and multimedia characteristics facilitate the navigation within the score and the creation of high quality content on the platform.

Collaborative aspects are also essential in music learning, where one progresses by confronting his performances to others'. In this frame, managing Signs rather than Knowledge is particularly relevant, as there is no "absolute truth" in artistic fields: each interpretation can lead to technical discussions between musicians, and their negotiations should be illustrated with live performances to be shown, then understood. This is why we introduced the notion of Musical Message Board (MMB) in [28]. MMBs support discussions between musicians through a Glosses' system, leading to the creation of a thread of MS indexed on some parts of the score (a note, a musical phrase, a measure, etc.). In addition to these indexed multimedia annotations, what distinguishes this MS thread from a discussion on the piece is that each of the created Signs is indexed in context and can then be reused in different situations, for instance, on another piece of music presenting similar features. To do so, the MSB should be able to grasp the basic sense of the created MS, in order to organize itself, and provide advanced Sign sharing functionalities to users. 


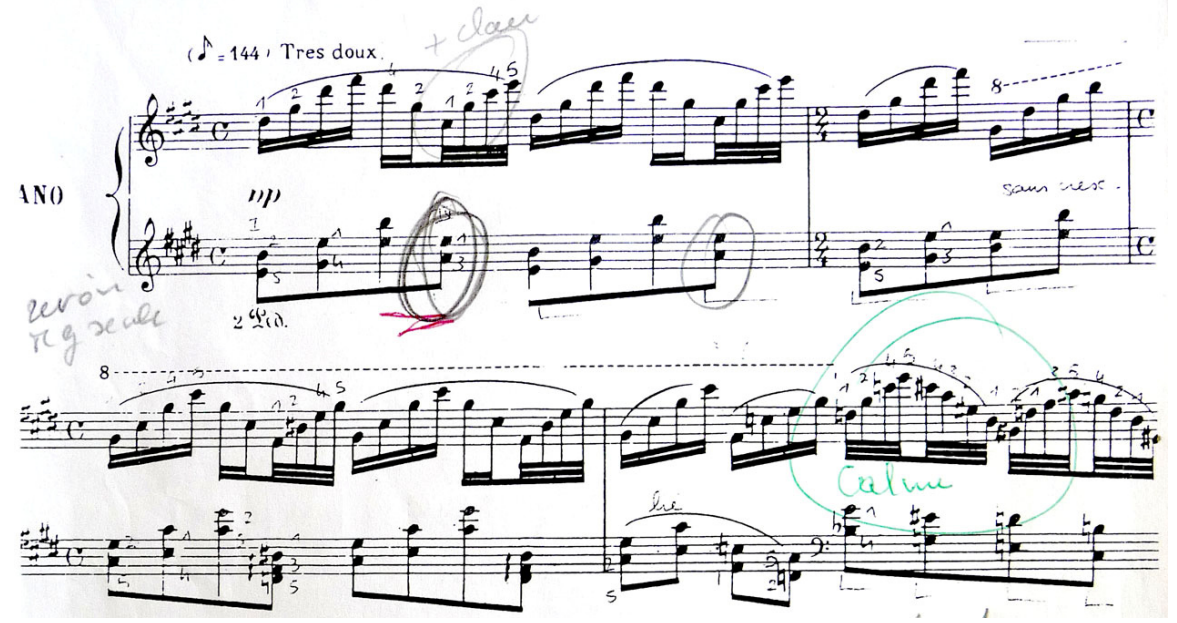

Fig. 7. Annotated score example (extract from "Jeux d'Eau” by Maurice Ravel)

Collecting MS on different pieces of music enables also the illustration of significant descriptive logics in order to organize the MSB. Descriptive logics of the semiotic Web are more meaningful than description logics of the semantic Web because they bring human interpretations (psychological annotations) on top of symbolic representations (formal notations). Indeed, in musical education, understanding the structure of a work is an important key to play it correctly. Musicology provides a guide for the musician to explore the piece in the finest details and to better assimilate it. But this structure can be lively exemplified with MS created by @-MUSE in the signification process of understanding the context of resolution of the musical piece.

Descriptive logics express the background knowledge of specialists who well understand the historical context of music playing. It often depends on the style or form of the considered piece, i.e. its classification. For instance, a fugue is based on a theme that is repeated all along the piece in different voices [30]. Underlining these themes within the score allows disposing of a framework to better analyze the corresponding performances and establish fruitful confrontations.

Figure 8 gives an example of an ontology based on descriptive logics (generic musical analysis).

This decomposition corresponds to the traditional way music teachers introduce a new piece to students [31]. After a short overview of the piece context (composer, style, mood), its characteristics patterns and difficult parts are identified and commented. This process can be recreated within the @-MUSE platform thanks to the characterization of descriptive logics adapted to each musical style. 

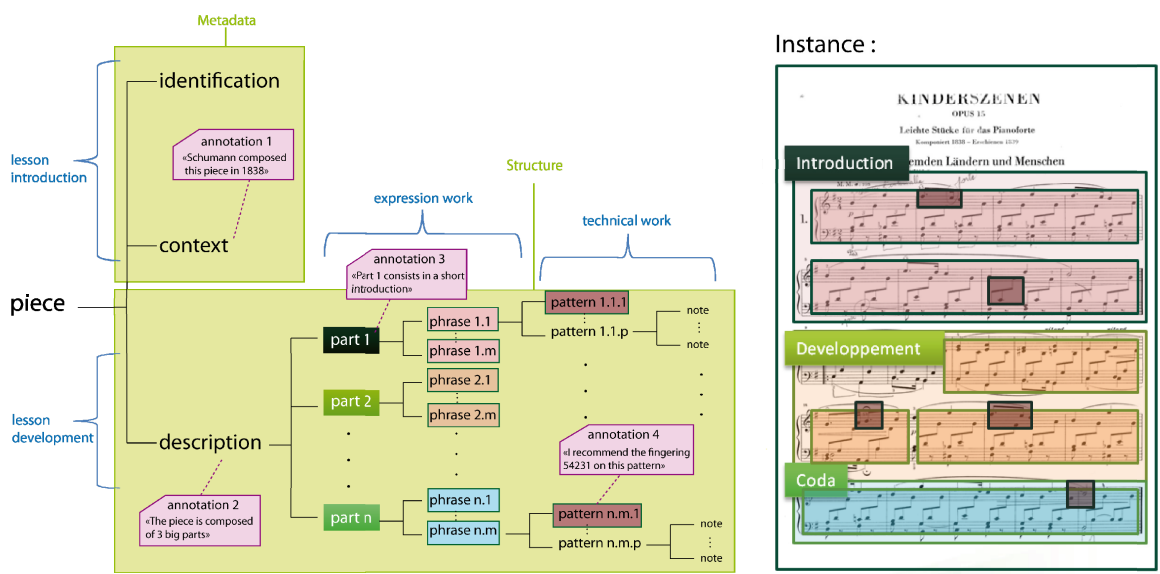

Fig. 8. The musical descriptive model supporting descriptive logics of the Semiotic Web

From the human-machine interaction point of view, it consists in proposing an "annotation guide" for each new piece, in order to obtain a complete interactive score at the end of the process. This method intends to guide users into the semiosis process described in Figure 2, by providing them a framework to communicate their own view of the considered piece and its characteristic features. In order to model these descriptive logics more formally, we proposed in [31] a Musical Performance Ontology based on the Music Ontology [32]. This ontology enables the automatic manipulation of concepts related to the piece structure, but also to gestural and expressive work. Tagging MS with these concepts and relations allows @-MUSE to automatically generate appropriate annotations on new pieces. Indeed, while machines can hardly deal with expressive and emotional information, they can provide basic information on specific patterns or unknown symbols, given a style or composer context. To do so, we designed a Score Analyzer [34] to automatically extract difficult parts within a given score, and to generate basic annotations. This prototype is based on the extraction of characteristic features of a score: chords, hands displacements, fingering, tempo, harmonies, rhythms and length. Work is in progress to measure the relevance of these estimations in comparison to human appreciations. As such, @-MUSE proposes an innovative service to share Musical Signs on a collaborative Web platform. The usage of multimedia and validated standards such as MusicXML empower users into illustrating specific parts of a musical work in a collaborative and reusable way. Perspectives of this research include further testing with musician collaborators from music schools, as well as work on decision support for automatic score annotation.

\section{Sign Sharing in Biodiversity Informatics}

Sharing Signs is also relevant in biodiversity management with ICT, in this specific domain called Biodiversity Informatics that applies computerized acquisition and processing methods to natural data, information and knowledge, in order to define, 
describe, classify and identify biological objects. More precisely, we focus on the scientific discipline called Systematics that deals with listing, describing, naming, classifying and identifying living organisms. Our natural objects are living specimens in the fields and in museum collections. Experts in Systematics at university or in museums have studied them intimately for years and are able to recognize their names that give access to more information in monographs.

In this frame, the IKBS project (Iterative Knowledge Base System) aims at constituting a Sign Base (SB) rather than a Knowledge Base (KB) with the interactions coming from a community of biologists and amateurs that want to share their interpretations of observations. This project will benefit from the long experience we accumulated in the field of Mascarene Corals and Plants identification [35].

\begin{tabular}{|c|c|c|}
\hline $\begin{array}{l}\quad \text { 1. Acquire } \\
\text { - Define a } \\
\text { descriptive model } \\
\text { - Build a } \\
\text { multimedia } \\
\text { questionnaire } \\
\text { - Describe } \\
\text { classified cases } \\
\text { (already } \\
\text { identified) }\end{array}$ & $\begin{array}{l}\text { 2. Process } \\
\text { Classify cases } \\
\text { by classification } \\
\text { methods } \\
\text { Discriminate } \\
\text { them by decision } \\
\text { trees } \\
\text { Identify them } \\
\text { with case-based } \\
\text { reasoning (nearest } \\
\text { neighbors) }\end{array}$ & $\begin{array}{l}\quad \text { 3. Validate } \\
\text { - Refine cases } \\
\text { and initial } \\
\text { descriptive model } \\
\text { - Update the old } \\
\text { cases with new } \\
\text { observations } \\
\text { Discover new } \\
\text { knowledge (new } \\
\text { classifications) }\end{array}$ \\
\hline
\end{tabular}

Fig. 9. Knowledge management cycle with IKBS

Figure 9 sums up our Knowledge transmission process in this domain, based on a Creativity Platform. It applies the experimental and inductive approach in biology, conjecture and test [36], with a natural process of knowledge management that is well suited to teaching from real examples. Indeed, IKBS has developed an original approach based on collection specimens' descriptions for helping specialists to discover new knowledge and classifications:

1. Acquisition of a descriptive model and descriptions,

2. Processing of this knowledge and case base for classification and identification purposes,

3. Experimentation, validation and refinement of cases and descriptive models,

4. Iteration.

For identification purpose, the expert controls the transmission process, which is detailed in Figure 10 for corals: 


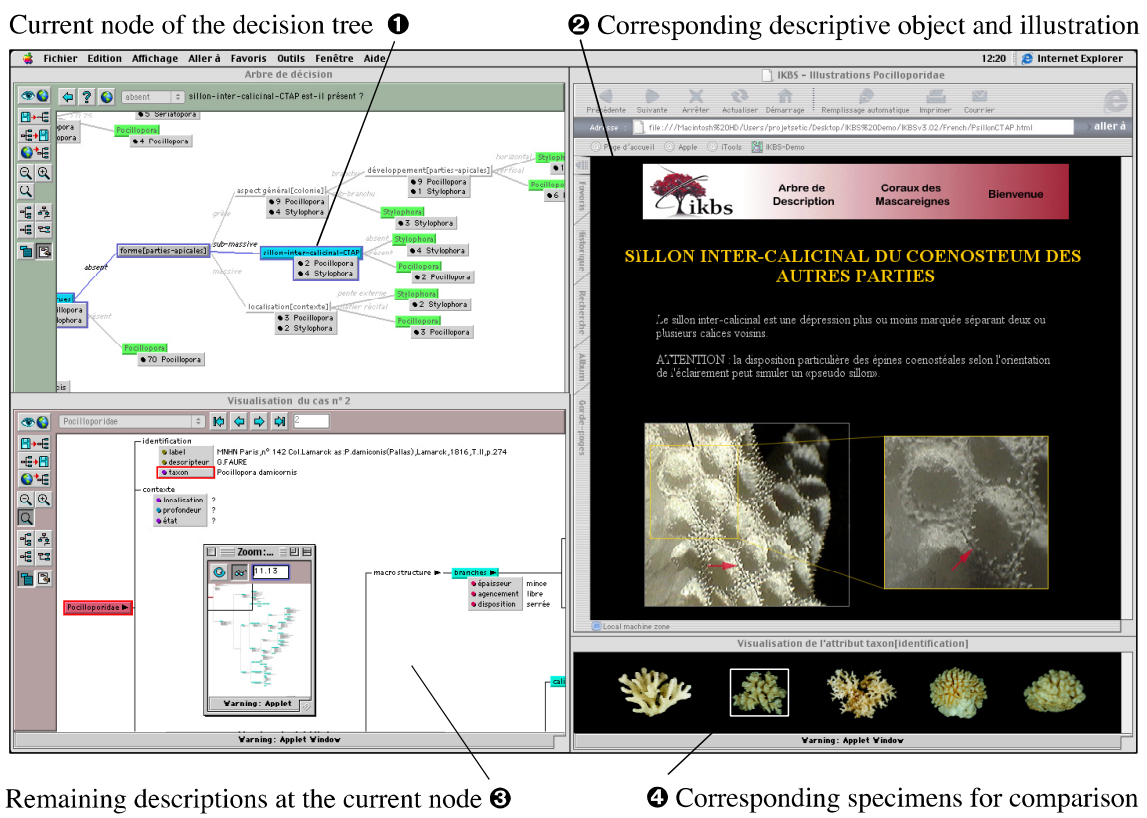

Fig. 10. The identification process for corals

- The actual node of the decision tree or identification key is shown (e.g. intercorallite's line),

- The referred question for this descriptive component and the illustrations of its possible values at this node are directly accessible (e.g. present or absent),

- One can leaf through the list of indexed cases at this node (e.g. cases of Pocillopora and Stylophora), in order to see the different values of the components and specimens,

- The pictures for the remaining objects at the current node are shown. The identification key may be useful to learn species' characteristics and improve one's ability to observe specimens in their natural surroundings or in a museum collection.

But the Learning problem from the end-user viewpoint is to know how to observe these objects in order to identify correctly the name of the species. This task is complex and needs help from the specialists who know by experience where to observe correctly the "right characters". By taking care of this knowledge transmission bottleneck, we enter the domain of Sign management for getting more robust results with end-users. Our idea of Sign management is to involve end-users with researchers and entrepreneurs for making them participate to the design of the product/service that they want.

The problem that we have to face with when making knowledge bases is that their usefulness depends on the right interpretation of questions that are proposed by the system to obtain a good result.

Hence, in order to get correct identifications, it is necessary to acquire qualitative descriptions. But these descriptions rely themselves on the observation guide that is 
proposed by the descriptive model. Moreover, the definition of this ontology is dependent upon easy visualization of descriptive logics.

At last, the objects that are part of the descriptive model must be explained in a thesaurus for them to be correctly interpreted by targeted end-users. Behind each Object, there is a Subject that models this Object and gives it an interpretation. In life sciences, these objects can be shown to other interpreters and this communication between Subjects is compulsory for sharing interpretations, and not only transmitting knowledge (Figure 11).

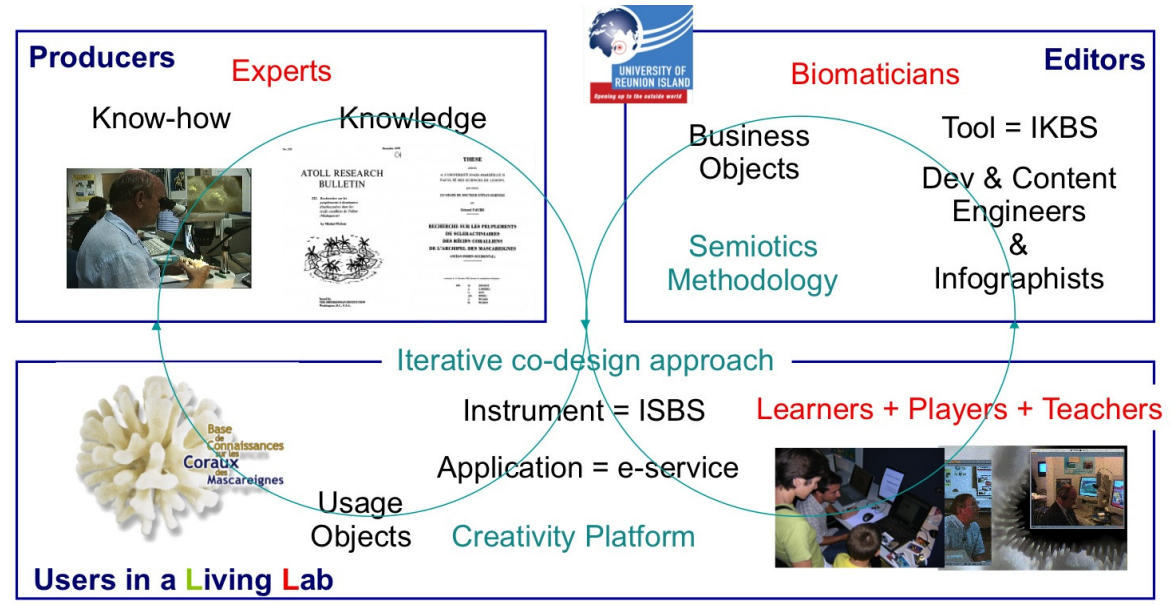

Fig. 11. The Sign management process for coral objects' interpretation

The challenge of Sign management for Science observation such as Systematics is to involve all types of end-users in the co-design of Sign bases for them to be really used (e-service). It is why we, as biologists and computer scientist (biomaticians), emphasize the instantiation of a Living Lab in Teaching and Learning at University of Reunion Island for sharing interpretations of objects and specimens on the table rather than concepts and taxa in the head of subjects: draw me a sheep, said the little prince !

\section{Discussion}

As shown in music and biodiversity Teaching and Learning, if we want to innovate with people, we should use the concept of Sign management rather than Knowledge management, because the paradigm shift is to pass from knowledge transmission to sign sharing by managing know-how.

Since several years in computer-aided systematics, we proposed a knowledge management methodology based on a top-down transmission of experts' knowledge, i.e. acquisition of a descriptive model and structured cases and then processing of these specimens' descriptions with decision trees and case-based reasoning. We designed a tool called IKBS for Iterative Knowledge Base System to build knowledge bases. But the fact is that Knowledge is transmitted with text, not shared with multimedia, and 
there is a gap between interpretations of specialists and end-users that prevents these lasts from getting the right identification.

More recently in instrumental e-Learning, we focused on the need to show gestural know-how with interactive multimedia contents to play correctly a piece of music, by annotating electronic scores with @-MUSE. This pedagogical approach is based on a gloss system on the Web that can be indexed in codified musical notation.

Today, we prefer to deliver a Sign management method for Teaching and Learning how to identify these collection pieces (specimens or scores) on a Co-Design or Creativity Platform. This bottom-up approach is more pragmatic and user-centered than the previous one because it implicates end-users at will and is open to questions and answers. The role of biological and musical experts is to show amateurs how to play, observe, interpret and describe these art and science works. The responsibility of semioticians (the new cogniticians) is to store and share experts' interpretations of their observation and playing, i.e. know-how rather than knowledge in sign bases with multimedia annotations for helping them to define terms, model their domain, and allow end-users to interpret correctly the objects.

As computer scientists and knowledge engineers, we want to design a new Iterative Sign Base System (ISBS) that will be the kernel of our Information Service for defining ontologies and terms, describing pieces work, classifying them with machine learning techniques, and identifying the name through a multimedia interactive questionnaire. The objective of such a tool is to become an instrument in users' hands for monitoring biodiversity in the fields with the National Park of Reunion Island, and music at home with the Regional Music Conservatory.

For achieving this, we stressed on the importance of reducing the gap between interpretations of teachers (specialists) and learners (amateurs) to get the right identification name and then access to information in databases, or to get the correct gesture that gives the right sound for playing music. This pedagogical effort must concretize itself on a Co-Design or Creativity Platform, which is the Living Lab meeting place for teachers, players and learners, and where these people can manipulate the objects under study, test the proposed e-services and be guided by experts' advices. The teacher is a producer who communicates his skilled interpretation of an activity at different levels of perception: psychological motivation, training action, and reasoning feedback. The players are designers-developers editors that produce multimedia contents of the expert tasks to perform a good result and index them in a sign base. The learners are prosumers (producers and consumers) who experiment the sign bases on the physical or virtual Co-Design Platform and tell about their use of the tool to domain experts, ergonomists and anthropologists, in order to improve the content and the functionalities of the mock-ups and prototypes.

Behind each Object to observe, play and describe, there is a Subject who expresses himself and interprets an object by adding his proper signification. This is why we differentiate the Semantic Web, which is the business object approach (the Web of things) represented "objectively" with some description logics (formal syntax for ontologies and cases), and the Semiotic Web that is the usage object approach (the Web of Signs) signified by some descriptive logics of the domain (meaningful process of performance), and which are more subjective. The purpose of the Semiotic 
Web is to facilitate a consensus between community members, without forgetting that some interpreters are smarter than others in performing a Science or an Art. Their expertise will be visible if users show their interpretations of objects by multimedia artifacts (HD video, 3D simulation, annotated drawings or photos), and if other endusers can ask questions on their know-how and negotiate interpretations. It is why in the frame of natural and cultural heritage enhancement, we proposed to develop Teaching and Learning by Playing e-services with people in a Living Lab by using Sign management on a Co-design Platform at the University of Reunion Island [37].

\section{Conclusion}

In the post-industrial age of our digital society, designing new services on the Web is crucial for regional territories in order that they become more attractive, competitive, and also more sustainable in the global economy. But up to now, innovation is mainly seen as a linear technological downstream process, centered on enterprises (clusters) and not viewed as an iterative usage upstream process, focused on individuals (Living Labs).

The form of LL is attractive because it is an ecosystem based on democratizing innovation with people. User-centered design innovation means that some people, called lead-users, want to innovate for themselves. It has been shown that these persons make most of the design of new services, and only a few come from manufactures.

The content of LL is competitive because the best solutions from lead-users are experimented in real time by making situational analyses in "usage laboratories". Mock-ups and prototypes are tested and instrumented to get the best-customizedpersonalized products and services. For example, the game design (user interaction) and interfaces of 3D multimedia video games benefit greatly from the analysis of feedbacks coming from end-users in communities of practice. So, the success of the eservice does not depend only on the technical success: it has more to do with the quality of human-computer interaction provided with the technology.

At last, the sense of LL should be more sustainable, i.e. to render a useful and free service before being profitable, i.e. not only based on a monetary basis but also on trust and reputation. This characteristic is fundamental in the meaning of open access innovation to serve a mission within the scope of products and services made by publicly funded universities. The ultimate value would be to create a form of digital companioning in order to reposition human sharing at the core of technology race.

Acknowledgments. We would like to thank the French National Government, the Regional Council of Reunion Island and the European Union for supporting this research in the frame of the PO-FEDER 2-06 ICT measure: http: / /www.reunioneurope.org/UE_PO-FEDER. asp. We are also grateful to the FP7 Vibrant project (www . vibrant . eu) contract no. RI-261532. Period, Dec. 2010 to Nov. 2013: they gave us the opportunity to develop our vision of sign management for biodiversity monitoring. This paper was presented at the ECAI/IFIP Artificial Intelligence for Knowledge Management Workshop (AI4KM) of ECAI'2012 (http: / / www2 . Iirmm. fr/ecai2012/) on the $28^{\text {th }}$ of August 2012 in Montpellier, France. 


\section{References}

1. http://en.wikipedia.org/wiki/Internet

2. http://www. openlivinglabs.eu/news/when-infrastructure-meetsuser-new-lovestory-making

3. http://www.ictusagelab.fr/ecoleLL/content/literature

4. Chesbrough, H.W.: Open Innovation: The New Imperative for Creating and Profiting from Technology. Harvard Business School Press, Boston (2003)

5. Von Hippel, E.A.: Democratizing Innovation. MIT Press, Cambridge (2005)

6. Keen, A.: The Cult of the amateur: How Today's Internet is Killing Our Culture, 228 p., Doubleday, New York (2007)

7. Lassila, O., Hendler, J.: Embracing "Web 3.0". IEEE Internet Computing 11(3), 90-93 (2007), doi:10.1109/MIC.2007.52

8. Peirce, C.S.: Elements of Logic. In: Hartshone, C.H., Weiss, P. (eds.) Collected Papers of C. S. Peirce (1839 - 1914). The Belknap Press, Harvard Univ. Press, Cambridge, MA (1965)

9. von Uexküll, J.: Theoretical Biology, pp. xvi+362. Kegan Paul, Trench, Trubner \& Co., London (1926) (Transl. by D. L. MacKinnon. International Library of Psychology, Philosophy and Scientific Method)

10. Farreny, H.: Les Systèmes Experts: principles et exemples: Cepadues-Editions, Toulouse (1985)

11. Shapiro, J.A.: Bacteria are small but not stupid: cognition, natural genetic engineering and sociobacteriology. Studies in History and Philosophy of Biological and Biomedical Sciences 38(4), 807-819 (2007)

12. Maslow, A.H.: A Theory of Human Motivation. Psychological Review 50(4), 370-396 (1943)

13. Engeström, Y.: Learning by expanding: an activity-theoretical approach to developmental research. Orienta-Konsultit Oy, Helsinki (1987)

14. Barbieri, M.: Introduction to Biosemiotics. The new biological synthesis. Springer (2007)

15. Sebeok, T.A., Umiker-Sebeok, J. (eds.): Biosemiotics: The Semiotic Web 1991. Mouton de Gruyter, Berlin (1992)

16. Saussure de, F.: Nature of the Linguistics Sign. In: Bally, C., Sechehaye, A. (eds.) Cours de Linguistique Générale. McGraw Hill Education (1916)

17. University of Reunion Island Living Lab vision (2011), http://www. slideshare. net/conruyt/urlitl

18. New Media Consortium (2013), http://www.nmc.org/publications

19. Conruyt, N., Sébastien, D., Vignes-Lebbe, R., Cosadia, S., Touraivane: Moving from Biodiversity Information Systems to Biodiversity Information Services. In: Maurer, L., Tochtermann, K. (eds.) Information and Communication Technologies for Biodiversity and Agriculture, Shaker Verlag, Aachen (2010) ISBN: 978-3-8322-8459-6

20. Vibrant FP7 Project (2011), http: / /vbrant. eu /

21. Conruyt, N., Grosser, D.: Knowledge management in environmental sciences with IKBS: application to Systematics of Corals of the Mascarene Archipelago. In: Selected Contributions in Data Analysis and Classification. Studies in Classification, Data Analysis, and Knowledge Organization, pp. 333-344. Springer (2007) ISBN: 978-3-540-73558-8

22. Le Renard, J., Conruyt, N.: On the representation of observational data used for classification and identification of natural objects. In: New Approaches in Classification and Data Analysis, Studies in Classification, Data Analysis, and Knowledge Organization, pp. 308315. Springer (1994) ISBN: 978-3-540-58425-4 
23. Conruyt, N., Sébastien, O., Sébastien, V., Sébastien, D., Grosser, D., Calderoni, S., Hoarau, D., Sida, P.: From Knowledge to Sign Management on a Creativity Platform, Application to Instrumental E-learning. In: 4th IEEE International Conference on Digital Ecosystems and Technologies, DEST, Dubaï, UAE, April 13-16 (2010)

24. Ryle, G.: The concept of mind. Hutchinson, London (1949)

25. Callaos, N.: The Essence of Engineering and Meta-Engineering: A Work in Progress. In: The 3rd International Multi-Conference on Engineering and Technological Innovation: IMETI 2010, Orlando, Florida, USA, June 29-July 2 (2010)

26. http://www.slideshare.net/conruyt/living-lab-and-digitalcultural-heritage

27. Sébastien, O., Conruyt, N., Grosser, D.: Defining e-services using a co-design platform: Example in the domain of instrumental e-learning. Journal of Interactive Technology and Smart Education 5(3), 144-156 (2008) ISSN 1741-5659

28. Sébastien, V., Sébastien, D., Conruyt, N.: Dynamic Music Lessons on a Collaborative Score Annotation Platform. In: The Sixth International Conference on Internet and Web Applications and Services, ICIW 2011, St. Maarten, Netherlands Antilles, pp. 178-183 (2011)

29. Winget, M.A.: Annotations on musical scores by performing musicians: Collaborative models, interactive methods, and music digital library tool development. Journal of the American Society for Information Science and Technology (2008)

30. Sébastien, V., Sébastien, P., Conruyt, N.: @-MUSE: Sharing musical know-how through mobile devices interfaces. In: 5th Conference on e-Learning Excellence in the Middle East, Dubaï (2012)

31. Sébastien, V., Sébastien, D., Conruyt, N.: An Ontology for Musical Performances Analysis. Application to a Collaborative Platform dedicated to Instrumental Practice. In: The Fifth International Conference on Internet and Web Applications and Services, ICIW, Barcelona, pp. 538-543 (2010)

32. Raimond, Y., Abdallah, S., Sandler, M., Giasson, F.: The Music Ontology. In: Proceedings of the International Conference on Music Information Retrieval, ISMIR (2007)

33. Castan, G., Good, M., Roland, P.: Extensible Markup Language (XML) for Music Applications: An Introduction. In: The Virtual Score: Representation, Retrieval, Restoration, pp. 95-102. MIT Press, Cambridge (2001)

34. Sébastien, V., Sébastien, D., Conruyt, N.: Constituting a Musical Sign Base through Score Analysis and Annotation. The International Journal on Advances in Networks and Services (2012)

35. http://coraux.univ-reunion.fr/, http://mahots.univ-reunion.fr/

36. Popper, K.R.: La logique de la découverte scientifique. Payot (eds.) Press, Paris (1973)

37. http://www openlivinglabs . eu/livinglab/university-reunionisland-living-lab-teaching-and-learning 